\section{$\underset{\substack{\text { hommes } \\ \text { \& migrations }}}{ }$}

\section{Hommes \& migrations}

Revue française de référence sur les dynamiques

migratoires

\section{$1285 \mid 2010$}

L'appel du pied

\title{
Nouvelles d'Afrique Nouvelles de foot, Enfants de la balle
}

Nouvelles réunies et présentées par A. A. Waberi, JC Lattès, 17 euros

\section{Élisabeth Lesne}

\section{(2) OpenEdition \\ 1 Journals}

\section{Édition électronique}

URL : http://journals.openedition.org/hommesmigrations/1214

DOI : 10.4000/hommesmigrations. 1214

ISSN : 2262-3353

Éditeur

Musée national de l'histoire de l'immigration

Édition imprimée

Date de publication : 1 mai 2010

Pagination : 199

ISSN : 1142-852X

Référence électronique

Élisabeth Lesne, « Nouvelles d'Afrique Nouvelles de foot, Enfants de la balle », Hommes \& migrations [En ligne], 1285 | 2010, mis en ligne le 29 mai 2013, consulté le 24 septembre 2020. URL : http:// journals.openedition.org/hommesmigrations/1214; DOI : https://doi.org/10.4000/

hommesmigrations. 1214

Ce document a été généré automatiquement le 24 septembre 2020.

Tous droits réservés 


\title{
Nouvelles d'Afrique Nouvelles de foot, Enfants de la balle
}

Nouvelles réunies et présentées par A. A. Waberi, JC Lattès, 17 euros

\author{
Élisabeth Lesne
}

\section{RÉFÉRENCE}

Nouvelles d'Afrique Nouvelles de foot, Enfants de la balle, Nouvelles réunies et présentées par A. A. Waberi, JC Lattès, 17 euros

1 Ils pourraient former une équipe de foot, ces onze écrivains nés en Algérie, au Maroc, à Djibouti, au Congo, au Togo, au Nigeria, à l'île Maurice et en Afrique du Sud. Mais, réunis par Abdourahman $\mathrm{A}$. Waberi, ils nous offrent quelque chose de bien plus rare qu'un match en ces temps de Coupe du monde : onze nouvelles qui restent dans la tête, onze fragments d'univers singuliers, quoique tous traversés, de façon plus ou moins fugace, par le ballon rond.

2 Dans "Esprit de corps", de Mark Behr, Douglas, père de famille, est réveillé en pleine nuit par un rêve. Émergeront peu à peu les images d'une scène traumatisante de son enfance : deux collégiens sont forcés de faire des pompes jusqu'à épuisement devant tous leurs camarades, parce qu'ils ont osé faire l'école buissonnière "pour aller sur le parking jouer au foot avec des nègres" - Nous sommes en Afrique du Sud...

3 Les deux nouvelles situées en Algérie sont d'une grande violence. Yahia Belaskri raconte dans "Blanc et noir" la balade d'après match d'un supporter ravi de la victoire de son équipe: viols et vols en série avec des potes avant le retour chez l'épouse apeurée et soumise. Quant à Anouar Benmalek, dans "Le penalty", il nous plonge dans la confusion mentale de Bachir : celui-ci assiste à un match de foot, mais sa mémoire lui joue des tours, et l'imam du coin, "un ancien délinquant d'au moins vingt-cinq ans", a profité de sa "tête qui pourrissait si vite" pour lui insuffler "la passion du djihad".

4 "Le clan des voleurs" de la Mauricienne Ananda Devi et "Ballon de poussière" du Congolais Wilfried N'Sondé évoquent les désillusions des jeunes joueurs repérés par des 
rabatteurs en Afrique. Amenés en Europe dans des centres d'entraînement, ils sombrent dans la détresse alors que leur famille s'étonne de ne pas les voir à la télé et de ne pas recevoir d'argent. "Soka mangea enfin à sa faim, mais dépérit de l'intérieur. [...] Curieusement, les attraits du monde occidental ne l'atteignaient pas. Il avait trop froid pour s'intéresser aux téléphones mobiles ou aux voitures, les boîtes de nuit où l'entrainaient ses coéquipiers lui apparurent comme des cauchemars sonores et visuels", écrit Ananda Devi.

5 Ces quelques exemples donnent une idée de la diversité de ce recueil. Rien à voir avec les commentaires des journalistes sportifs et les joueurs couverts de dollars, sûrement parce que la plupart de ces écrivains ont pratiqué dans leurs,jeunes années un football de pauvres, à l'instar de Waberi, qui écrit dans la préface : "Né dans un bidonville au plein mitan de Djibouti, le football a accompagné ma jeunesse et mon adolescence. Je me suis adonné à ce sport parce qu'il était le seul à ma portée: après tout on n'a besoin que d'un bout de plastique ou d'un tas de chiffon rassemblé en boule."

6 Ce livre est aussi une invitation à découvrir l'œuvre de ces onze écrivains présentés par une courte introduction, car tous ne sont pas encore aussi connus qu'Alain Mabanckou, qui signe dans ce recueil "Nous gagnerons la Coupe du monde 2010". 